2016

\title{
Promoting cognitive support technology use and employment success among postsecondary students with traumatic brain injuries
}

Phillip Rumrill

Kent State University

Eileen Elias

JBS International, Inc.

Deborah J. Hendricks

West Virginia University

See next page for additional authors

Follow this and additional works at: https://scholarscompass.vcu.edu/pmr_pubs

Part of the Medicine and Health Sciences Commons

(C) 2016 - IOS Press and the authors. All rights reserved

\section{Downloaded from}

https://scholarscompass.vcu.edu/pmr_pubs/9 


\section{Authors}

Phillip Rumrill, Eileen Elias, Deborah J. Hendricks, Karen Jacobs, Anne Leopold, Amanda Nardone, Elaine Sampson, Marcia Scherer, Callista Stauffer, and Brian T. McMahon 


\title{
Promoting cognitive support technology use and employment success among postsecondary students with traumatic brain injuries
}

Phillip Rumrill ${ }^{\mathrm{a}, *}$, Eileen Elias ${ }^{\mathrm{b}}$, Deborah J. Hendricks ${ }^{\mathrm{c}}$, Karen Jacobs ${ }^{\mathrm{d}}$, Anne Leopold ${ }^{\mathrm{b}}$, Amanda Nardone $^{\mathrm{d}}$, Elaine Sampson ${ }^{\mathrm{c}}$, Marcia Scherer ${ }^{\mathrm{e}}$, Callista Stauffer ${ }^{\mathrm{a}}$ and Brian T. McMahon ${ }^{\mathrm{f}}$

${ }^{\text {a }}$ Kent State University, Kent, $\mathrm{OH}, \mathrm{USA}$

${ }^{\mathrm{b}}$ JBS International, Inc., North Bethesda, MD, USA

${ }^{\mathrm{c}}$ West Virginia University, Morgantown, WV, USA

${ }^{\mathrm{d}}$ Boston University, Boston, MA, USA

${ }^{\mathrm{e}}$ University of Rochester, Rochester, NY, USA

${ }^{\mathrm{f}}$ Virginia Commonwealth University, Richmond, VA, USA

Revised/Accepted December 2015

\begin{abstract}
.
OBJECTIVE: This article applies positive psychology principles to the purpose and objectives of a five-year, federallyfunded initiative to provide cognitive support technology (CST) training and career preparatory services for undergraduate college students with mild and moderate traumatic brain injuries (TBI).

METHODS: A total of 48 students with TBI have participated in the project during its first 18 months of operation - 14 of whom are military veterans with disabilities who were in the Iraq and/or Afghanistan theaters.

CONCLUSION: Positive psychology interventions such as Best Possible Self, Intensely Positive Experiences, and Assetbased Assessments provide a framework for examining the activities of this multi-site development project.
\end{abstract}

Keywords: Traumatic brain injury (TBI), vocational rehabilitation (VR), assistive technology (AT)

\section{Introduction}

Traumatic brain injury (TBI) is the leading cause of death and lifelong cognitive disability among Americans under the age of 45 (Ashman, Gordon, Cantor, \& Hibbard, 2006). It is estimated that 1.7 million individuals in the United States (US) experience

*Address for correspondence: Phillip Rumrill, Ph.D., CRC, Professor \& Director, Kent State University Center for Disability Studies, 413 White Hall, P.O. Box 5190, Kent, OH 44242-0001, USA. Tel.: +1 330672 0600; Fax: +1 330672 2512; E-mail: Prumrill@kent.edu. a TBI each year (Faul, Xu, Wald, \& Coronado, 2010). Unfortunately, the prevalence of TBI is increasing among transition-age youth, that is, people between the ages of 16 and 25 (National Association of State Head Injury Administrators, 2006).

In $2009,248,418$ children were treated in the US for TBIs caused by sports and recreation-related activities. This statistic represents a 57\% increase since 2001 (Centers for Disease Control and Prevention [CDC], 2011). This increased incidence of TBIs among young people is occurring in addition to the high incidence of TBIs that are sustained as a result of 
military combat (Toriello, Bishop, \& Rumrill, 2012). The number of individuals who have experienced a TBI as a result of military service in Iraq and Afghanistan has been particularly difficult to estimate (Tanielian \& Jaycox, 2008). Some researchers place the estimates of American service members who have sustained a mild TBI while serving in Iraq and Afghanistan to be $10 \%-20 \%$, placing the actual number at more than 300,000 individuals (Brown, 2013; Hoge, Goldberg, \& Castro, 2009; Jorge et al., 2012). The Department of Defense reported that during 2014 alone, 22,738 service members worldwide had experienced a mild or moderate TBI (Defense and Veterans Brain Injury Center, 2015).

For individuals with TBI, the multi-systemic effects can dramatically influence their career aspirations, prospects for higher education, and community living choices (Wehman, Chen, West, \& Cifu, 2014; Wehman, Chen, Targett, West, \& Cifu, in press). As reported by Wehman (2013), for young people with TBI, these complications occur during critically important developmental periods when they are attempting to acquire training and make initial career choices. For veterans with TBI, these complications arise when they need to refresh their employment skills and re-enter civilian life.

Employment outcomes for individuals with TBI lag far behind those of the general population. Whether the brain injury is mild or more severe, many obstacles related to the physical, emotional, and cognitive symptoms of TBI prevent people from successfully finding and keeping jobs. Looking for job leads, keeping track of appointments, and going on interviews are frequently overwhelming. Once on the job, adapting to change and interacting with co-workers may become problematic. Forgetting a deadline, incorrectly processing a customer's order, or misinterpreting a supervisor's directive may affect the person's performance and job satisfaction (Johnstone, Inkowski, Farmer, \& Hagglund, 1994; Stock, 2006). Indeed, it has been reported that $75 \%$ of individuals with TBI who return to work lose their jobs within 90 days if they do not have adequate job retention supports such as assistive technology and other reasonable accommodations (National Association of State Head Injury Administrators, 2006).

The state-federal vocational rehabilitation (VR) program is the nation's oldest and largest provider of employment services for Americans with disabilities (Ditchman et al., 2013). The VR program spends more than $\$ 2.5$ billion per year for services ranging from assessment, diagnosis, medical services, and counseling to training, job placement, and job retention services (Chiu, Chan, Bishop, Cardoso, \& O'Neill, 2013). Unfortunately, individuals with TBI tend to underutilize VR services; only onethird of Americans with TBI have ever heard of the state-federal VR program, and only five to six percent receive state VR services (Sykes-Horn, Wrigley, Wallace, \& Yoels, 1997). Typically, VR services are provided only to individuals with moderate to severe TBI, which leaves many people with less severe TBI without options for vocational services and employment supports. Among service-eligible individuals with TBI who do avail themselves of state VR services, less than half (49\%) are successfully rehabilitated in competitive labor market employment. This success rate falls below those experienced by VR consumers with most other disabling conditions (Rumrill et al., 2015).

Even when an individual with TBI is successfully employed, he or she may need ongoing help when adapting to changes in job or life situations (Wehman, Targett, West, \& Kregel, 2005). Toriello and colleagues (2012) cited three major reasons for the difficulties individuals with TBI have in maintaining their careers post-injury: (a) he loss of social supports that often accompanies TBI, (b) changes in one's cognitive abilities as a result of injury, and (c) employers' lack of understanding of how to accommodate workers with TBI.

One approach for accommodating the changes resulting from a TBI comes from cognitive support technologies (CST), also known as assistive technologies for cognition (Adya, Samant, Scherer, Killeen, \& Morris, 2012; Bodine \& Scherer, 2006; Scherer, 2005a, 2012; Scherer \& Bodine, 2006; Scherer, Hart, Kirsh, \& Schulthesis, 2005). These products may be mainstream everyday technologies such as smartphones or they may be specialized devices designed for specific goals such as step-by-step instruction in the performance of a particular task (Scherer, 2012). Due to the variety and availability of these CST supports, and because of the unique needs of each individual with a brain injury, it is especially important to conduct a careful assessment of a potential user's needs; preferences; prior experiences with technology; and many other factors regarding the individual, the product, and the environment(s) of use (Bauer, Elsaesser, Scherer, Sax, \& Arthanat, 2014; Federici, Scherer, \& Borsci, 2014; Scherer, 2014; Scherer, Jutai, Fuhrer, Demers, \& DeRuyter, 2007). In keeping with the fundamental tenets of positive psychology, rehabilitation counselors are well 
positioned to conduct such assessments and provide the often-needed accompanying counseling and support services to maximize training for and benefit from CST use.

Higher education has long been viewed as an equalizer for individuals who experience disadvantages in seeking and securing employment. At first glance, this may be true for people with TBI. An individual with a TBI who holds a bachelor's degree is three times more likely to be employed than a person with a TBI who never attended college (Rumrill et al., 2015). However, postsecondary students with TBI, many of whom are young adults or returning combat veterans in the midst of other life transitions, face numerous academic and career preparatory challenges related to their cognitive, emotional, and psychosocial problems. The aggregate of these challenges results in lower grades in college and higher dropout rates compared to those reported by nondisabled students (Todis, Glang, Bullis, Ettel, \& Hood, 2011). Although about $80 \%$ of college and university students with TBI report problems performing in their academic settings, less than half report using campus disability services and only $20 \%$ report being aware of support services in the community (Kennedy et al., 2008). Two of the most prominent barriers reported by college students with TBI are: (a) limited access to assistive technology and (b) lack of career-related services to prepare them for the world of work after graduation.

Positive psychology has received increased attention in higher education settings (Parks, 2011). In the effort to help postsecondary students with TBI enhance cognitive functioning, build academic and vocational skills, increase social capital, expand their professional networks, and achieve positive academic and employment outcomes, the principles of positive psychology are used to provide an intervention framework for Project Career. Positive psychology is a contemporary paradigm for the helping professions that focuses on consumers' assets and virtues, not on their problems or limitations, as the targets of clinical interventions (Chapin, 2012). Whereas rehabilitation counseling and other human services fields have historically been criticized for emphasizing deficit-reduction and the medical model of disability (Smart, 2009), positive psychology holds that "treatment is not just fixing what is broken. Rather, it is nurturing what is best" (Seligman \& Csikszentmihalyi, 2000, p. 5). Recently, rehabilitation scholars have noted that the orientation of positive psychology is highly compatible with principles such as consumer empowerment, autonomy, self-advocacy, and self-determination, which are long-standing underpinnings of rehabilitation and independent living philosophy (Chapin, 2012; Chou, Chan, Chan, \& Phillips, 2013; Rubin \& Roessler, 2008; Rumrill \& Koch, 2014; Scherer, 2012; Strauser, 2013; Toriello \& Keferl, 2012; Wehman, 2013).

Positive psychology proponents maintain that client or consumer wellbeing comprises physical, social, financial, career, and community domains (Rath \& Harter, 2010; Chapin, 2012). Although some of these domains may be related to one another within a particular individual, they operate as distinct factors in people's overall health and perceived quality of life. For example, a worldwide Gallup study using the Wellbeing finder indicated that $66 \%$ of people reported thriving in one of the areas of wellbeing, but only seven percent were thriving in all areas (Rath \& Harter, 2010).

The purpose of this article is to describe a fiveyear, multi-site development project funded by the National Institute on Disability, Independent Living, and Rehabilitation Research (NIDILRR) to promote CST use and individualized vocational support for undergraduate college and university students with TBI. The project's mission and direct-service components are cast according to the principles of positive psychology.

\section{Project overview}

Project Career is a five-year (2013-2018), collaborative development project among Kent State University, Boston University, JBS International, Inc., and West Virginia University, funded by the NIDILRR. The goal of Project Career is to develop, implement, and test a technology-driven, long-term, and resource-rich individualized support program that merges CST and VR practices to improve the career readiness and employment outcomes of civilian and veteran undergraduate students with TBI who are enrolled in 2- and 4-year colleges and universities. Across the five-year work plan, Project Career endeavors to yield evidence-based practices that address the cognitive and vocational needs of this population, thereby providing an integrated and holistic approach for improving the long-term employment outcomes of undergraduate college and university students with TBI.

Across the three implementation sites in Massachusetts, Ohio, and West Virginia, Project Career 
recruits a total of 30 undergraduate students with TBI each year. These students include both veterans who served in Iraq and/or Afghanistan and civilians. Optimally, participants begin working with the project in their freshman year and continue through graduation and the transition to employment, although students may enroll in the project at any point during their undergraduate education. To date, the project has served 48 students with TBI, 14 of whom are military veterans $(29.2 \%)$. Students are referred to Project Career by college and university offices such as disability services for students, career services, and veteran support services; the US Department of Veterans Affairs; state VR agencies; acute and postacute health care facilities; and disability advocacy organizations. Although students may self-refer to the project, they must be able to provide adequate medical documentation of ongoing impairments due to TBI.

Once enrolled in the project, students begin working closely with a Technology and Employment Coordinator (TEC) at their respective implementation site. The TECs conduct a baseline assets assessment (e.g., confidence about choosing a career, ability to secure information related to career choice) and a comprehensive CST assessment (Scherer, 2005b). Results of the CST assessment tool are used to develop a customized, technology-driven intervention built on the use of a CST device for providing individualized cognitive, psychosocial, and educational supports in conjunction with a cadre of sequenced vocational rehabilitation services. An iPad, a handheld tablet computer provided by Project Career to each participating student, serves as the CST device. A major component of the CST assessment is the completion of several measures in the Matching Person and Technology portfolio that are designed to identify incentives and barriers to iPad use emerging from personal factors, characteristics of the environments of use, and those of the device itself (Scherer, 2005b). Specific cognitive supports are delivered in the form of iPad applications (apps) related to cognitive enhancement, especially in the areas of memory, attention, and organizational skills (Scherer, 2012).

The iPad is also used by the Project Career TECs as a tool to provide virtually-based and individualized career-related training, education, counseling, guidance, and mentoring using an intensive case management model. The role of such services in achieving successful employment outcomes is well established (Roessler \& Rubin, 2006). Participating students receive individual training from TECs at their sites on how to use the iPad and apps.

The primary purpose of Project Career is to address many of the barriers to gaining and maintaining employment that confront individuals with TBI in their efforts to lead independent and self-reliant lives. These barriers include the disability itself, lack of education or training, limited use of assistive and general-use technology to accommodate the cognitive impairments caused by TBI, lack of role models within the disability community, and negative perceptions of employers (Bureau of Labor Statistics, 2011). Results to date from Project Career suggest that this technology-driven intervention is effective in promoting academic success, retention or persistence in college, and career preparatory activities; only five of the 48 students who enrolled in Project Career during the first 18 months of project operations have withdrawn from the project, representing a $90 \%$ retention rate. Moreover, two of the five students who have withdrawn from Project Career without completing their academic degrees are gainfully employed in their chosen career fields as of this writing.

Among rehabilitation professionals (e.g., rehabilitation counselors, secondary transition specialists, and occupational therapists), there is broad consensus that accommodation aids or CSTs, such as iPad applications, are among the most effective ways of helping individuals with cognitive impairments cope with everyday life (Scherer, 2012). Despite their cognitive impairments, individuals with TBIs have often proven able to master electronic tools to help them function effectively in educational and employment settings. In addition, younger people with cognitive impairments have found such tools to be of great personal and social benefit (Wehman, 2013). Research indicates that this population requires assistance and training to improve their vocational skills and employability, and that CSTs are essential for gaining and maintaining such skills to perform tasks accurately and independently (Carrol, 1993; Sauer, Parks, \& Heyn, 2010; Wehmeyer et al., 2003). Specifically, results of a systematic review of the literature showed that all studies investigating the effects of CSTs on employment outcomes demonstrated positive effects, including increased accuracy, independence, and generalization of skills (Sauer, Parks, \& Heyn, 2010). Moreover, universal CST devices (i.e., devices used by individuals with and without disabilities) are becoming less expensive, easier to use, and socially valid in mainstream settings, thereby supporting the assertion that they should be 
introduced in academic settings to support students with TBI. This is the premise upon which the Project Career intervention was developed.

In addition to serving as a CST device to enhance Project Career students' cognitive and academic capacities, iPads are used by the TECs and others (e.g., mentors) to deliver vocational support services such as electronic mentoring (e-mentoring), case management, assistance in obtaining and maintaining field-based work placements, consultation regarding career readiness and the transfer of academic accommodations into the professional workplace, job placement, and support in post-graduation employment. Facilitated by the Project Career TEC who has regular electronic and in-person contact witssh each student, these services have previously been shown to be effective in improving employment outcomes for a variety of disability populations (Wehman, 2013). In this project, these services are significantly enhanced by the individualized CST skills training and by the mentoring received by each student participating in the project. Each Project Career student can elect to be assigned a mentor in his or her field of endeavor. This professional role model guides the student's career preparatory activities in conjunction with the TEC.

A great deal of research exists on the impact of early work experience for the transition of young people with disabilities from school to work at the secondary and postsecondary levels (Wehman, 2013; Wehman et al., 2015). The literature in this area is especially rich with a variety of studies completed on the impact of early work experience on both long-term employment and earnings outcomes. The transition from college and university programs into the labor market is often viewed as path dependent; that is, the quality of the initial entry into the labor market after completion of formal postsecondary education exerts a strong long-term impact on the employment and earnings outcomes of college graduates. Therefore, a major thrust of Project Career is to provide hands-on practical experience for each participating student in his or her career field. Part-time jobs, summer employment, and fieldbased internships are strongly encouraged as a way to gain "real world" experience while completing one's formal training. Project Career mentors are instrumental in helping participating students assess career plans, make professional contacts, and identify possible sites for practical work experiences.

With its focus on the use of iPads as CST devices and tools to deliver a variety of educational support and career readiness services, Project Career is providing much-needed best-practice data regarding the use of technology in career-preparatory programming for postsecondary students with TBI. One end product of Project Career will be a compendium of best practices on the use of CSTs as a rehabilitation and postsecondary education intervention tool, technology application guidelines, training and procedural manuals, and resource information that rehabilitation professionals and individuals with TBI can utilize to enhance the technology and mentoring proficiency, academic success, self-determination, and long-term career outcomes for civilian and veteran students with TBI.

Another important feature of Project Career is its National Advisory Board, which includes eight national leaders in TBI rehabilitation programming, advocacy, and/or research in both the civilian and military systems. Convening twice annually via web conferences, the Board offers important guidance and consultation regarding the currency, validity, and responsiveness of the CST and career-preparatory interventions. Importantly, more than half of the Board members have personal or family experience with TBI, which greatly enhances the authenticity of project activities.

\section{Positive psychology and project career}

To the extent that physical wellbeing includes the functioning of body systems and the physical, sensory, and psychological activities of daily living (Chapin, 2012), the CSTs used in Project Career represent positive psychology interventions (PPIs) that enhance physical and psychological wellbeing. Upon enrollment in Project Career, each student undergoes a comprehensive, Assets-based Assessment of his/her cognitive and academic abilities. During this assessment, the site's TEC guides the student through a series of questions and activities to determine his or her level of competence in areas necessary for a positive higher education experience. Following this assessment, CST strategies are identified to enhance and strengthen areas of cognition (e.g., memory, attention, organization) and other physical areas (e.g., stress levels) that may have been compromised by the student's TBI. Supporting and enhancing students' cognitive and other capabilities through the use of iPads and iPad applications increase their organizational, academic, personal, social, and vocational assets. Preliminary findings indicate that project participants have an increase in satisfaction with their 
academic experience, decreased negative affect, less resistance to change, and improved feelings of positive support.

Outside of the classroom, Project Career students use their iPads to gather important information on topics such as new medical and mental health treatment options, available exercise and wellness programs, nutrition, and more. All of these areas of interest have the potential to enhance the student's physical and psychological wellbeing. In positive psychology parlance, Project Career services enable participating students to realize their Best Possible Selves - self images that are grounded in optimism for future success rather than in past or present disabilityrelated limitations (King, 2001).

Project Career offers a number of benefits to participating students' social wellbeing. First and foremost, the iPad provides a single platform for communicating with other people through text messages, e-mail, social media websites, and videoconferencing. All of these modalities have the effect of increasing students' social capital, which is a well-documented correlate of both employment outcomes and perceived quality of life (Blanck, 2014; White et al., 2010). The improved information technology skills resulting from participation in Project Career increase students' effective and timely communication with others (e.g., other students, faculty, and potential employers). Data collected to date indicate that participating students have increased positive experiences using the technology over time and more positive feelings about the technology.

Project Career services further expand students' social networks by introducing them to mentors in their chosen career fields, by encouraging them to join professional organizations and attend professional conferences, and by arranging work experiences in integrated community settings. In the latter endeavor, the social experience of interacting with co-workers, customers, and employers is invaluable. Chapin (2012) emphasized the importance of providing authentic work experiences as a part of any positive psychology vocational rehabilitation program, noting that these experiences provide essential opportunities for consumers to demonstrate their strengths and talents and to familiarize themselves with the culture of work in their chosen fields. In these ways, the opportunity to interact with influential career role models constitutes an Intensely Positive Experience (Chapin, 2012) for participating students.

Inherent in positive psychology is the notion that success leads to success. In other words, an Intensely
Positive Experience with an employer, a co-worker, a mentor, a faculty member, or a Project Career TEC builds the student's confidence and raises his or her expectations for positive experiences in other project activities and in other social situations.

The impact of Project Career on students' career wellbeing is somewhat self-explanatory by virtue of the title of the project. The CST platform of the iPad and cognitive enhancement applications build important academic and intellectual skills, which improve students' grades and retention rates according to preliminary project findings. Improved grades and retention rates increase graduation rates, which are important in light of the positive relationship between educational attainment and competitive employment among individuals with TBI (Rumrill et al., 2015). In addition, Project Career uses a tried and true intensive case management model and career preparatory services (e.g., mentoring program, job-seeking skills training, structured work experiences, consultation regarding classroom and workplace accommodations, self-advocacy training, interface with college career services offices, selective job placement services, and post-graduation follow-up services) combined with the CST training to significantly enhance students' prospects for career success after college graduation. Here again, the concept of the Best Possible Self applies (King, 2001). Students are encouraged to identify their ideal or "dream" jobs, and the mentors provide important real-world perspectives on the demands and requirements of students' desired occupations. Preliminary findings indicate that Project Career students experience improved career decision-making self-efficacy, lessened concerns about encountering barriers to career progress, and better acceptance of the longterm effects of TBI.

Project Career assessments, interventions, and activities are strength-based rather than problemfocused. Students are encouraged to develop their assets and talents through their academic programs, work experiences, extracurricular and community activities, and personal exploration. Selfdetermination skills are emphasized in all interactions with students, beginning with exercising their own choices regarding the services and supports they will receive as part of the project. Mentors help students identify and demonstrate their strengths and talents, and job-seeking skills training enables students to polish their skills in articulating their positive assets. In keeping with the self-determination orientation of the project, participating students complete progress 
assessments at six-month intervals, an important component of which asks them to rate their satisfaction with project services and make suggestions for any improvements. In keeping with continuous quality improvement principles that underlie the Project Career plan of evaluation, student feedback is carefully considered in the refinement and modification of project activities.

The majority (60\%) of Project Career students to date were not employed at the time of enrollment in the project. Many of these students reported limited work experience since their injuries, and the devastating financial impact of TBI is well documented (Thurman, 2001). Not surprisingly, therefore, Project Career students often express concerns about their current and future financial wellbeing. Students' improved prospects for competitive employment after graduation have obvious positive effects on their future financial wellbeing, and the increased optimism they exhibit regarding their economic self-sufficiency after college graduation is an important positive psychology virtue. Also, Project Career staff members often provide consultation and technical assistance to help students understand the provisions and limitations of any disability benefits they receive, including the impact that paid employment might have on their benefits. This is an example of enhancing self-determination skills.

Project Career services also have a beneficial impact on participating students' community wellbeing. These students use their iPads to connect with TBI and veteran support groups in their locales; to identify assistive technology and accommodation strategies that can be used at home, in class, and/or in the workplace; and to identify housing and transportation resources that maximize their options for full participation in their communities. Project Career students may also use their iPads to purchase goods and services, arrange travel and recreational activities, register to vote, read newspapers, and obtain news and other important information - all of which increase their capacities for active citizenship and help make community life an Intensely Positive Experience (Chapin, 2012).

\section{Conclusion}

With its abiding focus on each student's assets, strengths, and virtues, Project Career can be viewed as a positive psychology intervention for postsecondary students with TBI as they pursue their academic and career goals. This five-year initiative builds important personal, social, academic, and vocational capacities for participating students through the use of cognitive support technology in the form of iPads and a set of iPad applications selected to meet each student's needs. The dual emphasis on modern, universal technology and career preparation addresses two of the most prominent academic and vocational barriers reported by individuals with TBI. The mentoring that Project Career offers provides important introductions to professional role models who help students realize their Best Possible Selves and make the college years an Intensely Positive Experience.

\section{Acknowledgments}

The contents of this article were developed under a grant from the United States Department of Education, NIDRR grant \#H133A130066. However, those contents do not necessarily represent the policy of the Department of Education, and readers should not assume endorsement by the Federal Government.

\section{Conflict of interest}

None to declare.

\section{References}

Adya, M., Samant, D., Scherer, M. J., Killeen, M., \& Morris, M. W. (2012). Assistive/rehabilitation technology, disability, and service delivery models. Cognitive Processing, 13(1) Supplement, 75-78.

Ashman, T. A., Gordon, W. A., Cantor, J. B., \& Hibbard, M. R. (2006). Neurobehavioral consequences of traumatic brain injury. Mt Sinai Journal of Medicine, 73(7), 999-1005.

Bauer, S., Elsaesser, L. J., Scherer, M., Sax, C., \& Arthanat, S. (2014). Promoting a standard for assistive technology service delivery. Technology and Disability, 26(1), 39-48.

Blanck, P. (2014). The struggle for web equality by persons with cognitive disabilities. Behavioral Sciences and the Law, 32, 4-32

Bodine, C. \& Scherer, M. J. (2006). Technology for improving cognitive function. A workshop sponsored by the US Interagency Committee on Disability Research (ICDR): Reports from working groups. Disability and Rehabilitation, 28(24), 1567-1571. PMID: 17178621

Brown, J. (2013). Veterans with mild traumatic brain injury have brain abnormalities. Iowa Now. Retrieved from http:// now.uiowa.edu. 
Bureau of Labor Statistics. (2011). Persons with disability: Labor force characteristics - 2011. USDL-12-1125. United States Department of Labor.

Carroll, J. M. (1993). Creating a design science of humancomputer interaction. Interacting with Computers, 5, 3-12.

Centers for Disease Control and Prevention. (2011). Nonfatal traumatic brain injuries related to sports and recreation activities among persons aged $\leq 19$ years — United States, 2001-2009. MMWR, 60(39), 1337-1342.

Chapin, M. H. (2012). The role and participation of people with disabilities in the new American workplace. In P. J. Toriello, M. L. Bishop, \& P. D. Rumrill (Eds.), New directions in rehabilitation counseling: Creative responses to professional, clinical, and educational challenges (pp. 236-254). Linn Creek, MO: Aspen Professional Services.

Chiu, C. Y., Chan, F., Bishop, M., Cardoso, E., \& O’Neill, J. (2013). State vocational services and employment in multiple sclerosis. Multiple Sclerosis, 19(12), 1655-1664.

Chou, C. C., Chan, F., Chan, Y. C., \& Phillips, B. (2013). Introduction to positive psychology in rehabilitation. Rehabilitation Research, Policy, \& Education, 27, 126-130.

Chou, C. C., Chan, F., Chan, Y. C., Phillips, B., Ditchman, N., \& Kaseroff, A. (2013). Positive psychology theory, research, and practice: A primer for the rehabilitation counseling professionals. Rehabilitation Research, Policy, \& Education, 27, 131-153.

Defense and Veterans Brain Injury Center. (2015). DoD numbers for traumatic brain injury worldwide-Totals. Retrieved from http://dvbic.dcoe.mil/sites/default/files/DoDTBI-Worldwide-Totals-2014-Q1-Q4-Feb23-2015.pdf.

Ditchman, N., Wu, M., Chan, F., Fitzgerald, S., Lin, C. P., \& Tu, W. (2013). Vocational rehabilitation. In D. Strauser (Ed.), Career Development, Employment, and Disability in Rehabilitation: From Theory to Practice (pp. 343-360). New York: Springer Publishing Company.

Faul, M., Xu, L., Wald, M. M., \& Coronado, V. G. (2010). Traumatic Brain Injury in the United States: Emergency Department Visits, Hospitalizations and Deaths 2002-2006. Atlanta, GA: Centers for Disease Control and Prevention, National Center for Injury Prevention and Control.

Federici, S., Scherer, M. J., \& Borsci, S. (2014). An ideal model of an assistive technology assessment and delivery process. Technology and Disability, 26(1), 27-38.

Hoge, C. W., Goldbert, H. M., Castro, C. A. (2009). Care of war veterans with mild traumatic brain injury-Flawed perspectives. New England Journal of Medicine, 360, 1588-1591.

Johnstone, B., Inkowski, M., Farmer, J., \& Hagglund, K. J. (1994). Neurobehavioral deficits, adolescent traumatic brain injury and transition to college. Journal of Clinical Psychology in Medical Settings, 1, 375-386.

Jorge, R. E., Acion, L., White, T., Tordesillas-Gutierrez, D., Pierson, R., Crespo-Facorro, B., \& Magnotta, V. (2012). White matter abnormalities in veterans with mild traumatic brain injury. American Journal of Psychiatry, 169(12), 12841291.

Kennedy, M. R. T., Krause, M. O., \& Turksta, L. S. (2008). An electronic survey about college experience after traumatic brain injury. NeuroRehabilitaiton, 23, 511-520.

King, L. A. (2001). The health benefits of writing about life goals. Personality and Social Psychology Bulletin, 27, 798-807.

National Association of State Head Injury Administrators. (2006). Traumatic Brain Injury Facts: Vocational Rehabilitation and
Employment Services. Retrieved on December 16, 2014 from http//www.nashia.org.

Parks, A. C. (2011). The state of positive psychology in higher education: Introduction to the special issue. Journal of Positive Psychology, 6, 429-431.

Rath, T., \& Harter, J. (2010). Wellbeing: The five essential elements. New York: Gallup Press.

Roessler, R., \& Rubin, S. (2006). Case management and rehabilitation counseling: Procedures and techniques. Austin, TX: Pro-Ed.

Rubin, S., \& Roessler, R. (2008). Foundations of the vocational rehabilitation process, 6th edition. Austin, TX: Pro-Ed.

Rumrill, P., \& Koch, L. (2014). Vocational rehabilitation counseling. In P. Hartung, M. Savickas, \& B. Walsh (Eds.), American Psychological Association Handbook of Career Intervention (pp. 139-155). San Francisco, CA: American Psychological Association Books.

Rumrill, P., Wehman, P., Cimera, R., Kaya, C., Dillard, C., \& Chan, F. (2015). Vocational rehabilitation services and outcomes for transition-age youth with traumatic brain injuries. Journal of Head Trauma Rehabilitation. Advance online publication.

Sauer, A. L., Parks, A., \& Heyn, P. C. (2010). Assistive technology effects on the employment outcomes for people with cognitive disabilities: A systematic review. Disability and Rehabilitation: Assistive Technology, 5(6), 1-15.

Scherer, M. J. (2014). From people-centered to person-centered services, and back again. Disability and Rehabilitation: Assistive Technology, 9(1), 1-2. PMID: 24304239

Scherer, M. J. (2012). Assistive technologies and other supports for people with brain impairment. New York: Springer Publishing Company, LLC.

Scherer, M. J. (2005a). Assessing the benefits of using assistive technologies and other supports for thinking, remembering and learning. Disability and Rehabilitation, 27(13), 731-739. PMID: 16096225

Scherer, M. J. (2005b). The Matching Person \& Technology (MPT) Model and Assessment Process. CD-ROM. Webster, NY: The Institute for Matching Person \& Technology, Inc.

Scherer, M. J., \& Bodine, C. (2006). Technology for improving cognitive function: Report on a workshop sponsored by the U.S. Interagency Committee on Disability Research. Disability and Rehabilitation: Assistive Technology, 1(4), 257-261. PMID: 19260173

Scherer, M. J., Hart, T., Kirsch, N. \& Schulthesis, M. (2005). Assistive technologies for cognitive disabilities. Critical Reviews ${ }^{\mathrm{TM}}$ in Physical and Rehabilitation Medicine, 17(3), 195-215.

Scherer, M., Jutai, J., Fuhrer, M., Demers, L., \& DeRuyter, F. (2007). A framework for modelling the selection of assistive technology devices (ATDs). Disability and Rehabilitation: Assistive Technology, 2(1), 1-8. PMID: 19263548

Seligman, M. E. P., \& Csikszentmihalyi, M. (2000). Positive psychology: An introduction. American Psychologist, 55(1), 5-14.

Smart, J. (2009). Disability, society, and the individual (2nd ed.). Austin, TX: Pro-Ed.

Stock, S. (2006). Employment for Persons with Brain Injuries in Oregon. Salem, OR: Oregon Competitive Employment Project Oregon State Department of Human Services, Office of Vocational Rehabilitation Services.

Strauser, D. (2013). Career Development, Employment, and Disability in Rehabilitation. New York: Springer Publishing Company. 
Sykes-Horn, W., Wrigley, M., Wallace, D., \& Yoels, W. (1997). Factors associated with awareness of vocational rehabilitation services after traumatic brain injury. Archive of Physical Medicine and Rehabilitation, 78, 1327-1330.

Tanielian, T., \& Jaycox, L. H. (2008). Invisible wounds of war: Psychological and cognitive injuries, their consequences, and services to assist recovery. Santa Monica, CA: RAND Corp.

Thurman, D. J. (2001). Epidemiology and economics of head trauma. In L. Miler \& R. Hayes (Eds.), Head trauma: Basic, preclinical, and clinical directions (pp. 1193-1202). New York: Wiley and Sons

Todis, B., Glang, A., Bullis, M., Ettel, D., \& Hood, D. (2011). Longitudinal investigation of the post-high school transition experiences of adolescents with traumatic brain injury. Journal of Head Trauma Rehabilitation, 26(2), 138-149.

Toriello, P., Bishop, B., \& Rumrill, P. (2012). New Directions in Rehabilitation Counseling. Lake of the Ozarks, MO: Aspen Professional Services.

Toriello, P. J., \& Keferl, J. E. (2012). A renaissance of consumer autonomy: Moving from self-determination theory to therapy. In P. J. Toriello, M. L. Bishop, \& P. D. Rumrill (Eds.), New directions in rehabilitation counseling: Creative responses to professional, clinical, and educational challenges (pp. 1-24). Linn Creek, MO: Aspen Professional Services.

Wehman, P. (2013). Life Beyond the Classroom (5th ed.). Baltimore, MD: Paul H. Brookes Publishing Co.
Wehman, P., Chen, C., West, M., \& Cifu, G. (2014). Transition planning for youth with traumatic brain injury: Findings from the National Longitudinal Transition Survey-2. NeuroRehabilitation, 34(2), 365-372.

Wehman, P., Sima, A. P., Ketchum, J. M., West, M., Chan, F., \& Luecking, R. (2015). Predictors of transition from school to employment for youth with disabilities. Journal of Occupational Rehabilitation, 25, 323-334.

Wehman, P., Chen, C., Targett, P., West, M., \& Cifu, G. (in press). Transition planning and postsecondary education for youth with TBI. Journal of Postsecondary Education and Disability, in press.

Wehman, P., Targett, P., West, M., \& Kregel, J. (2005). Productive work and employment for persons with traumatic brain injury: What have we learned after 20 years? Journal of Head Trauma Rehabilitation, 20(2), 115-127.

Wehmeyer, M. L., Smith, S. J., Palmer, S. B., Davies, D. K., \& Stock, S. E. (2003). Technology use and people with mental retardation. In L.M. Glidden (Ed.), International review of research in mental retardation. San Diego, CA: Academic Press.

White, G. W., Simpson, J. L., Gonda, C., Ravesloot, C., \& Coble, Z. (2010). Moving from independence to interdependence: A conceptual model for better understanding community participation of centers for independent living consumers. Journal of Disability Policy Studies, 20(4), 233-240. 
Copyright of Journal of Vocational Rehabilitation is the property of IOS Press and its content may not be copied or emailed to multiple sites or posted to a listserv without the copyright

holder's express written permission. However, users may print, download, or email articles for individual use. 